\title{
Risk-based management of chemicals and products in a circular economy at a global scale- Impacts of the FP7 funded project RISKCYCLE
}

Veit Grundmann ${ }^{1 *}$, Bernd Bilitewski ${ }^{1}$, Antje Zehm ${ }^{1}$, Rosa Mari Darbra ${ }^{2}$ and Damià Barceló ${ }^{3}$

\begin{abstract}
The project RISKCYCLE ("Risk-based management of chemicals and products in a circular economy at a global scale") was funded by the European Union Framework Program 7 ("FP7"). It started in 2009 and its aims were successfully accomplished by the end of the project, three years later (2012). Within this coordination action a consortium of international experts investigated and defined the future research needs and gaps of for innovation in the field of risk-based management of chemicals and products.

Various potential hazardous chemicals are used as additives in products worldwide. By developing new chemicals and product management approaches, the risks for human health and the environment should be minimized. As a first step, existing information about usage, risks, chemical properties and labelling chemicals and especially additives in consumer and industrial products were assembled and evaluated. RISKCYCLE focused on the fate and behaviour of these additives in six sectors: textile, electronics, plastics, leather, paper and lubricants. Additionally the project aimed at developing alternative testing strategies to minimize animal testing.

The following article summarizes the background, the aims and issues and the most important outcomes of the EU funded project RISKCYCLE. It gives a brief overview about how the issues arise within a circular economy, how the project partners worked together in a coordination action and how results and conclusions were obtained.
\end{abstract}

\section{Introduction}

The project RISKCYCLE ("Risk-based management of chemicals and products in a circular economy at a global scale") was funded by the European Union Framework Program 7 ("FP7"). It started in 2009 and its aims were successfully accomplished by the end of the project, three years later (2012). Within this coordination action a consortium of international experts investigated and defined the future research needs and gaps of for innovation in the field of risk-based management of chemicals and products.

Various potential hazardous chemicals are used as additives in products worldwide. By developing new chemicals and product management approaches, the

\footnotetext{
* Correspondence: Veit.Grundmann@tu-dresden.de

${ }^{1}$ Technische Universität Dresden, Institute of Waste Management and Contaminated Site Treatment, Pratzschwitzer Str. 15, 01796, Pirna, Germany Full list of author information is available at the end of the article
}

risks for human health and the environment should be minimized. As a first step, existing information about usage, risks, chemical properties and labelling chemicals and especially additives in consumer and industrial products were assembled and evaluated. RISKCYCLE focused on the fate and behaviour of these additives in six sectors: textile, electronics, plastics, leather, paper and lubricants. Additionally the project aimed at developing alternative testing strategies to minimize animal testing.

\section{Background of the project}

The global trade of chemicals and products containing chemical additives (such as paint, cosmetics, household cleaners, paper and cardboard, plastic toys, textiles, electronic appliances, petrol, lubricants etc.) has resulted in a substantial release of harmful substances to the environment with risk to man and nature on a worldwide 
scale. Detailed information about the global flows of recycling products are scarce and difficult to investigate.

Figure 1 shows a simplified material flow in a circular economy at global scale with its risks for health and the environment in consequence of the worldwide trade of chemicals and products. The new threat is coming from closing the loop in a global scale. Plastic, paper and cardboard, lubricants and other products undergo a recycling process and make their ways into recovered materials, causing unpredictable and not foreseeable health and safety problems.

Politicians in Europe and worldwide started to take action on chemical management and risk minimizing when they started to be aware of the fact that humans and the environment are exposed to chemical risks on a daily basis. The discussion of the assessment and management of chemicals and products at the 1992 Earth Summit in Rio de Janeiro led for example to the creation of the OECD ("Organisation for Economic Co-operation and Development") programme "Globally Harmonized System of Classification and Labelling of Chemicals" ("GHS"). Further harmonization of the chemicals legislation in Europe was done in 2007 by "REACH" ("Registration, Evaluation, Authorisation of Chemicals") entering into force. Currently there are additional discussions about possible improvements of REACH legislation, which should be decided by the end of 2012. RISKCYCLE aimed at contributing to influence the development of REACH, by providing gained results and concluded needs regarding the management and labelling of chemicals.

\section{Circular economy}

The concept of a Circular Economy describes the transformation of traditional patterns of economic growth and production. The conventional perception of economic systems is that they are linear. The linear system is converted to a circular system when the relationship between resource use and waste residuals is taken into consideration.

In the year 1996 the German parliament passed the worldwide first law on Circular Economy and since then a number of comments demanded its revision. This law was revised in 2012 focusing now even more on the management of waste as valuable resource and its material flow.

The German government has still been guided by the ideas that waste and pollution prevention are the foremost aims to develop a circular economy. The prevention could be reached by a change of production technologies to cleaner production. Further on the better reuse and recycling of waste and better and more recycling friendly construction of goods are demanded to fulfil higher recycling rates.

Although there are already good examples at national level, new threats arise from closing global substance cycles. The trade of products of unknown specification and ingredients will cause unsafe consumer and industrial goods arriving on the global market. An exemplary compound with oestrogenic activity, which has already been extensively studied and which is formed as an intermediate in the production of polycarbonate and epoxy resin, is Bisphenol A (BPA) (Figure 2).

Toxic substances in WEEE (Waste Electrical and Electronic Equipment) may include for example heavy metals, such as lead, mercury and cadmium or organic halogen compounds, such as polychlorinated biphenyls (PCBs) and brominated flame retardants (BFRs). Currently it is estimated that up to $80 \%$ of electronic waste is being transported illegally from developed countries into developing countries in Asia and Africa, where they are recycled and prepared for re-use due to lower labour costs and lack of control of environmental rights.

A closer look on paper and cardboard recycling cycles shows that endocrine disruptors are increasingly

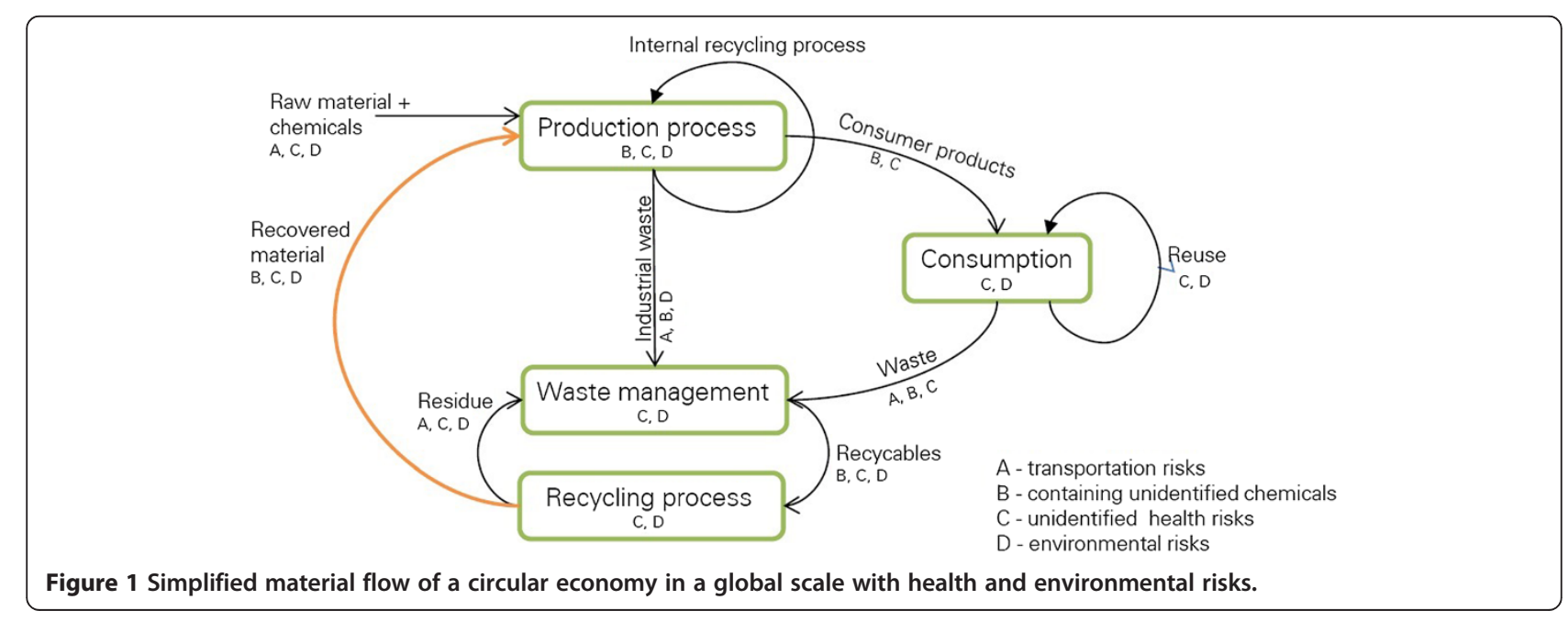




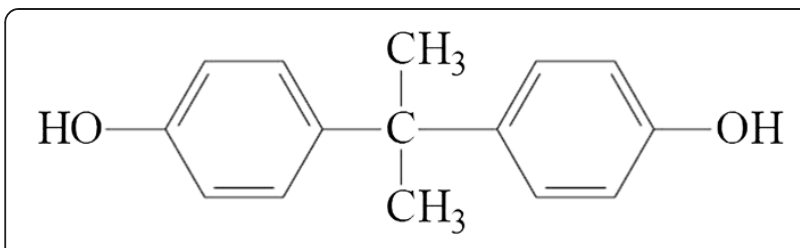

Figure 2 2, 2-Bis-(4-hydroxyphenyl)propan (Bisphenol A, BPA) [1].

introduced into the paper cycle, for example the already mentioned BPA, by recycling used thermal papers. BPA may be subsequently detected in recycled paper and within the next product or within waste water (toilet paper). Printing inks used in newspaper printing may result in contamination of cardboard packaging for food industry and thus enter the human food chain [2].

Using these hazardous substances is partly already banned or restricted in Europe. Due to the international trade of products and also from lower production standards, unforeseeable health and safety problems may occur. All these examples show that in a circular economy, global trade is inacceptable without a globally agreed risk assessment for existing and new chemicals and products.

\section{Collaboration in a coordination action}

Under direction of Prof. Bernd Bilitewski (Technische Universität Dresden) and Prof. Damià Barceló (Spanish National Research Council (CSIC), Barcelona) five international conferences have been organized over the past three years. Among others the main aim of the workshops was to give the 16 project partners and the representatives from the Advisory Board of the project (e.g. OECD, UNEP (United Nations Environment Programme), SAICM (Strategic Approach to International Chemicals Management)) the possibility to discuss country-specific problems and research results together with international and also local politicians and representatives. The outcomes of these workshops have been included into the main tasks of the single work packages of RISKCYCLE and in the created reports and publications. The presentations, pictures and proceedings of the single RISKCYCLE conferences are available as download on the project website.

The first two conferences were held in May 2010 in Hanoi (Vietnam) and in November 2010 in Shenyang (China), with an enormous amount of $70-100$ participants each (see Figure 3). In 2011 the second two international conferences were held in May 2011 in Rio de Janeiro (Brazil) and in October 2011 in New Delhi (India). Due to their local organization, an interesting mix of international speakers and topics could be presented. Research results, which are usually written and published in foreign languages and thus difficult to obtain, have been made publicly available to a broad European audience and provided versatile and valuable input to the project.

The final RISKCYCLE conference, titled "Risk-Based Management of Chemicals and Products in a circular economy at a global scale", was held on $8^{\text {th }}$ and $9^{\text {th }}$ May 2012 in Dresden (Figure 4).

Selected results of investigations and case studies have been introduced and presented. The conference was divided into two days. On the first day the aim of the conference was among others to introduce the main aims of the project RISKCYCLE, to present flows and emissions of additives - from production to reuse, recycling and waste, the fate and behaviour of chemical additives in recycling products and alternative toxicity testing for additives in products to reduce animal test in line with the objectives of the REACH directive.

The second day of the conference dealt with several risk assessment methodologies, mitigation strategies for human

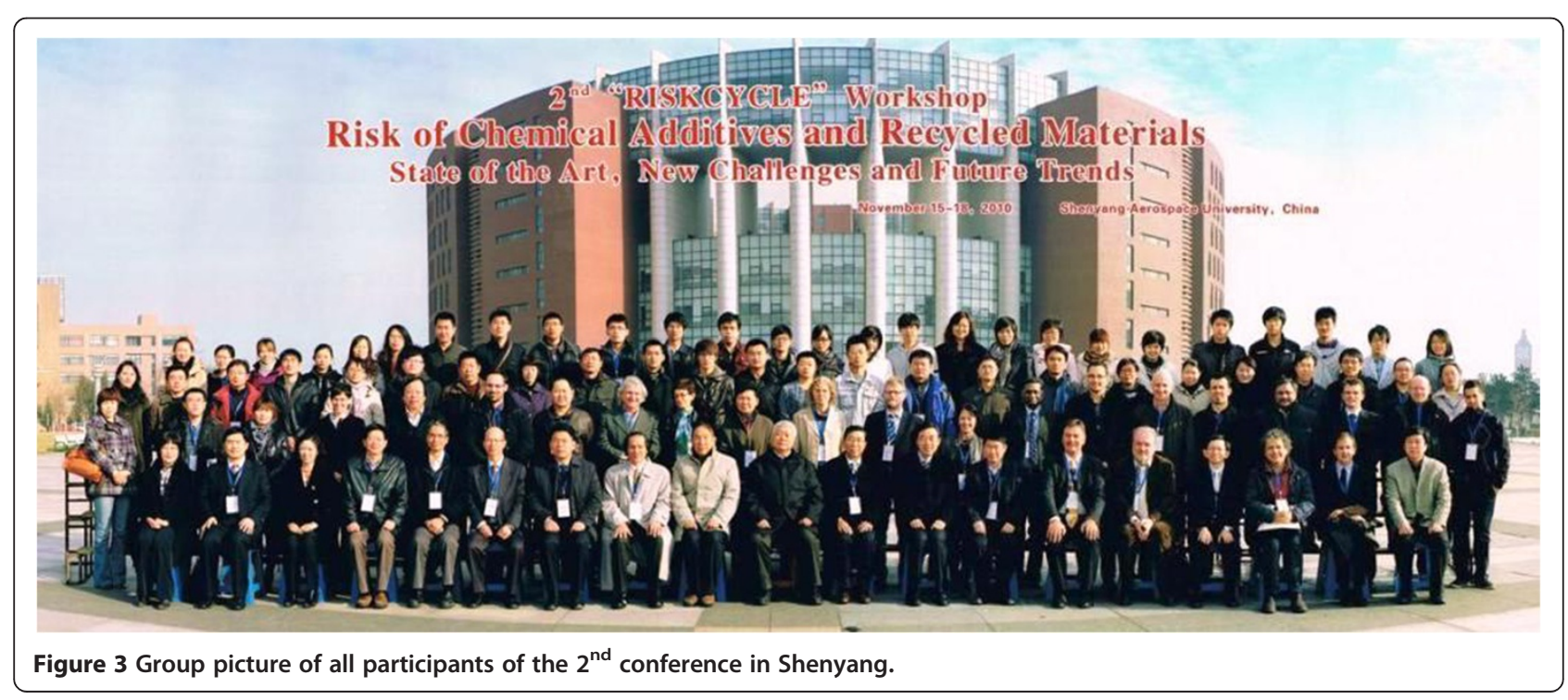




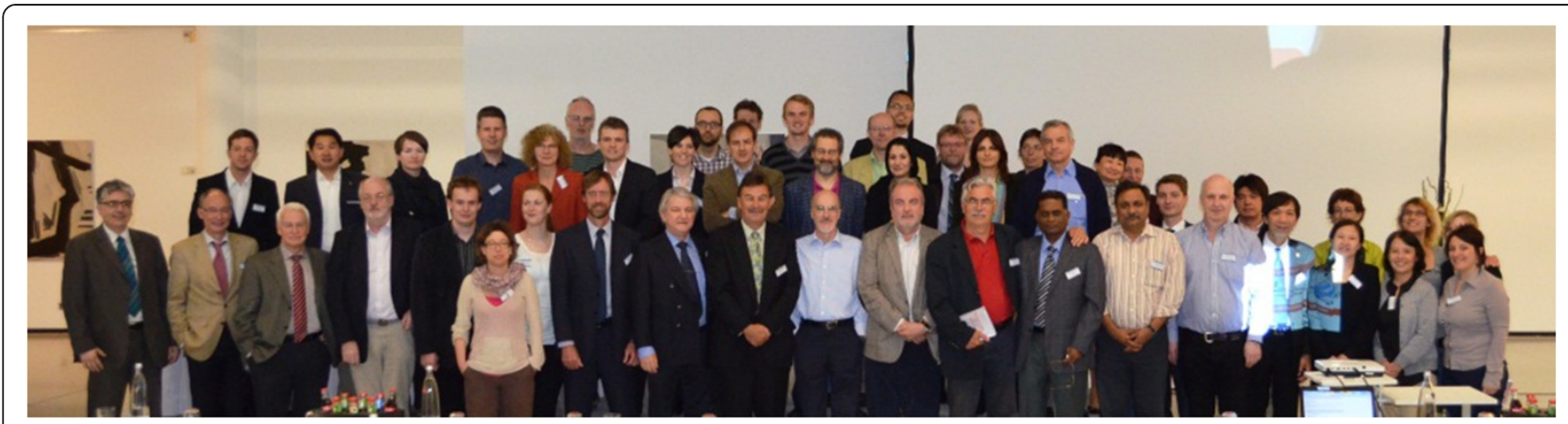

Figure 4 Group picture of all participants of the final RISKCYCLE conference in May 2012 in Dresden.

health and environment related to additives, the importance of additives in life cycle assessment (LCA) of textiles, electronics, plastics, leather, paper and lubricants and also attempted to bridge research needs with policy in the field of risk-based management of chemicals and products.

The final RISKCYCLE conference was concluded every day with a final discussion led by the work package leaders and speakers. Together with the audience, the contents of the presentations and further on the needs of future research activities in the field of risk-based management of chemicals and additives were discussed. The papers about the presentations and also the poster presentations were included in the proceedings [3] of the conference, which are available via the website of the conference organizers.

\section{Strategy, results and conclusions}

In the application phase and during discussions of the project proposal, the project partners already determined the six fractions, which should be investigated in detail within the project. In the beginning of the project the most dangerous substances and additives for each of the six considered fractions were set by means of literature research and analysis. Various scientific publications were scanned for information about the main important additives and their hazardousness and during the ongoing course of the project and the intensive individual work packages they were further examined. By publishing the results in books (Vol.I and II), in workshop proceedings, as download on our website and also during various presentations, the project results were spread and presented to a broader audience, which lead to discussions of the results also with external researchers and institutions (Figure 5).

Within the project, leather and textile industries, different additives, dyes and tannins, influencing the properties, were object of observation. The chemicals Nonylphenol, Bisphenol-A and various biocides were determined as pernicious and significant additives within these six sectors and therefore special attention was paid to them. Within the leather industry also heavy metals, such as Chromium, were investigated more in detail. In addition the use of flame retardants, particularly brominated flame retardants, were analysed within the electronic and textile industry. The use of PFOS, PFOA and NPAA in the lubricants industry and the use of phthalates (DEHP), lead and organotin were also in the focus of the project activities.

After choosing the main additives for the six fractions, different methodologies to assess risks were applied within several case studies. The results were assessed and were also published as reports of the single project work packages on our website, as presentations during conferences and as book chapters.

The cooperation of international experts within the various work packages, targeted at using different approaches when dealing with the core issues of RISKCYCLE to develop a common strategy using the gained knowledge. The individual work packages of the project include for example identifying alternative testing methods for chemicals and additives in products, to avoid the enlargement of animal testing; risk assessment methodologies, as well

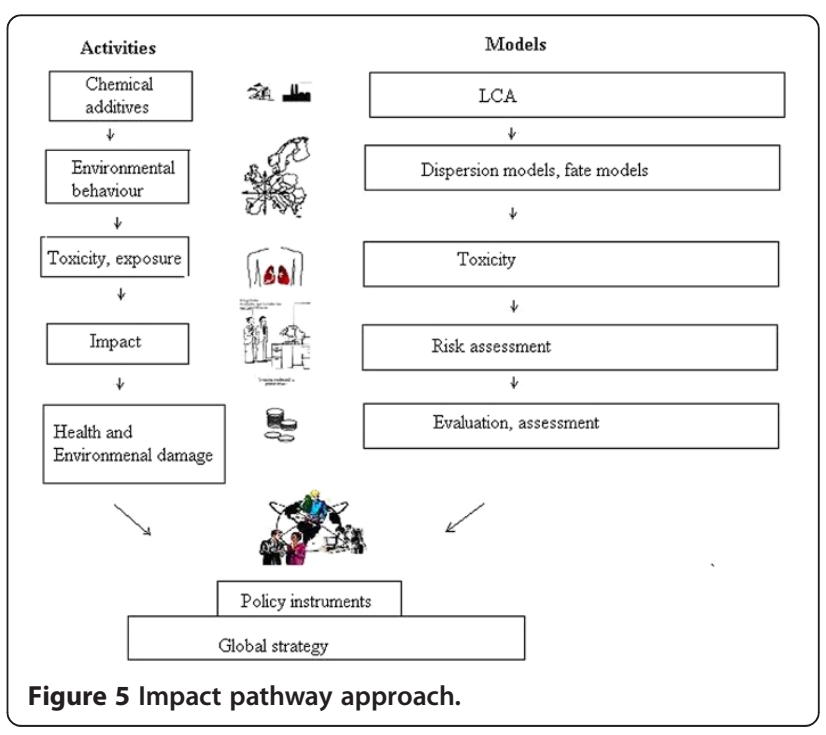


as the consideration of life cycle assessment of and socioeconomic aspects, occurring due to unintended appearance of additives.

Based on the results of the assessments within the projects work packages and also based on further discussions, the key elements for a global strategy for riskbased management of chemicals and products and the future research needs and gaps were defined.

\section{Conclusion and Future Impact of the project RISKCYCLE}

The aim of the coordination with a consortium of European and overseas experts was to investigate and define the future research needs and gaps in this field. The following bullets show some of the research needs and gaps, which were considered to be important by the work package responsible persons:

- Lack of data about chemicals in products

- Risk of chemical mixtures

- Release of chemicals from materials and goods

- Scarce information on characteristics related to the use of chemicals

- Associated uncertainty is missing for in vivo experiments

- Necessity to increase the acceptability on alternative methods

- Missing common database for additives in the WEEE

- Limited specific data about informal recycling processes (efficiency, emissions)
- Lack of information about additives in products in LCA databases

- More detailed emission models for products need to be developed

- Necessity to establish the link between emissions and impacts of a substance

What are the outcomes of the RISKCYCLE project and how is the influence on research policy and legislation? Different ways for implementation are conceivable: the Ecodesign Directive, European Waste Legislation (RoHS, WEEE, and REACH).

The Ecodesign Directive is the regulation that sets the standards for products in principle for the pre-consume phase, so that only those chemical additives may be added that do not cause problems in a sustainable closed material and substance cycle. Currently the Directive is being discussed to expand its scope, and not only to products related to energy consumption.

Since the implementation of the RoHS (Restriction of Hazardous Substances) Directive many problems have already been addressed and hazardous components have been limited or banned. The outcome of the RISKCYCLE project and further research initiatives could be a reason to extend the scope of the Directive either by a broader scope (not only electrical and electronic equipment) or by extending the catalogue of restricted substances (Annex II of the Directive).

According to the European Chemicals Legislation (REACH) manufacturer and importer have to register chemicals they are bringing on the European market, if
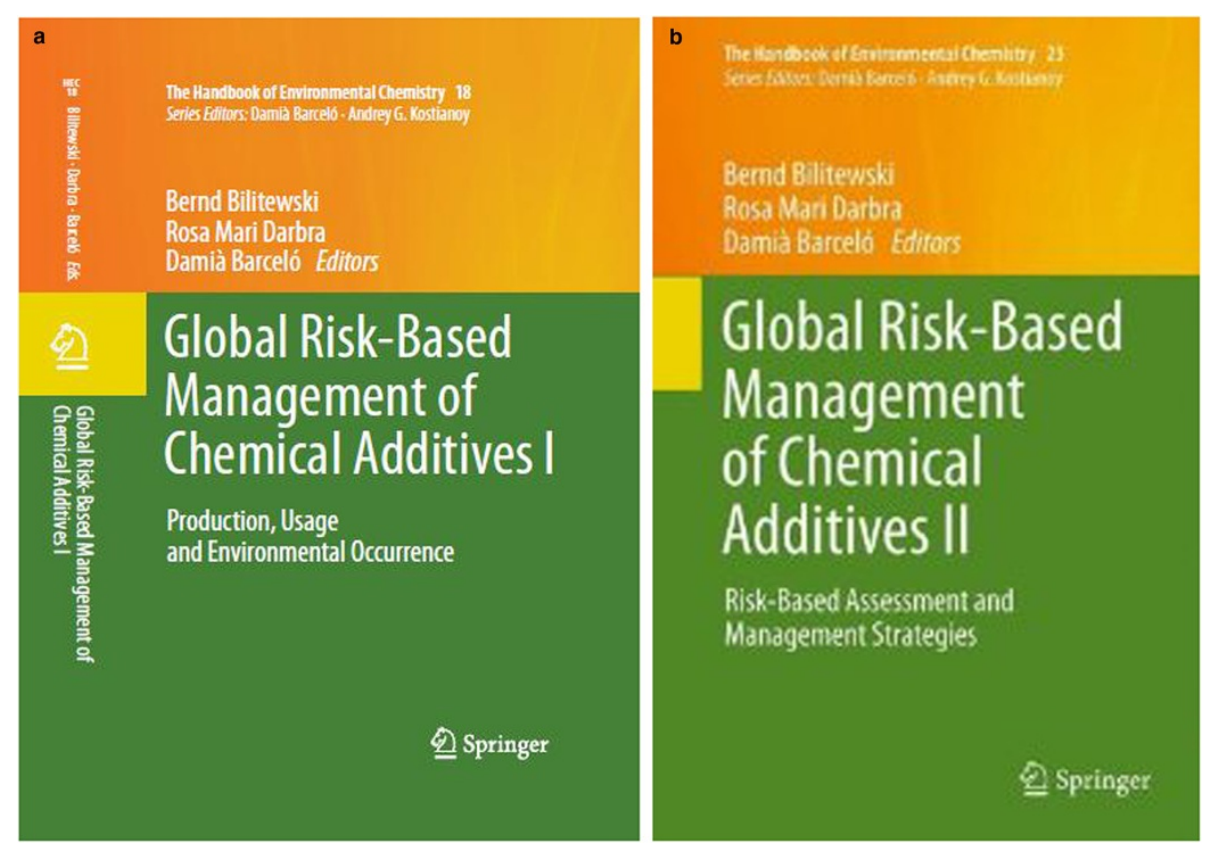

Figure 6 Cover of the RISKCYCLE book Vol. I and Vol II. 
the sold volume exceeds more than $1 \mathrm{Mg} / \mathrm{a}$. The REACH regulation has the item that after a five years period there should be an evaluation of the regulation itself - this is where the results of the project RISKCYCLE and followup research could give more information to the European legislation As soon as a material or a waste 'ceases to be waste', it becomes instead a product and is falling under the REACH regulation. Actually the Commission is working on establishing end-of-waste criteria for a number of specific recyclable materials. With regard to the outcome of RISKCYCLE, the obligations for products containing hazardous substances are of great concern, a risk characterisation is mandatory.

\section{Publication of the results}

The homepage of the project RISKCYCLE (www.wadef. com) already provides the following reports and will soon be updated with the latest results and reports.

- Overview of environmental factor influence over additive exposure and release into the environment

- Review of models for predicting the concentration of chemicals in air, water and soil to human exposure, including mathematical and functional specification of the multimedia software

- Report containing a discussion on the identified criteria and their scores for alternative methods

- List of databases and meta-databases

- Report on the review of bioassays and biosensors and $(\mathrm{Q})$ SAR models as candidate for the intended use

- Definition of risk scenarios and historical analysis

- Life Cycle Assessment of additives

- Meta-analysis of damage costs related to health, the built environment and the ecosystem

For each of the considered six fractions a list with five main additives, which were studied in detail, was compiled. Using these selected additives, exemplary investigations were carried out within the single work packages, such as Life cycle assessment of additives in the plastics and paper industries, or the use of different risk assessment methodologies to investigate the effects of using these additives and their behaviour in various recycling processes. The results of these investigations and the first project outcomes are published in the book "Global Risk-Based Management of Chemical Additives I (Production, Usage and Environmental Occurrence)" [4] (Figure 6).

Additional results of the second project period were published at the beginning of 2013 as part of the book, "Global Risk-Based Management of Chemical Additives II: (Risk-Based Assessment and Management Strategies)" [5]. All other reports are also available as download on the project homepage (www.wadef.com).
"The project RISKCYCLE receives funding from the European Community's Seventh Framework Programme under grant agreement n ${ }^{\circ}$ FP7-226552".

\section{Competing interests}

The authors declare that they have no competing interests.

\section{Authors' contributions}

$V G, B B, A Z, R M D, D B$ conceived of the study and participated in its design and coordination and helped to draft the manuscript. All authors read and approved the final manuscript.

\section{Author details}

${ }^{1}$ Technische Universität Dresden, Institute of Waste Management and Contaminated Site Treatment, Pratzschwitzer Str. 15, 01796, Pirna, Germany. ¿Universitat Politècnica de Catalunya, Center for Technological Risk Studies, Barcelona, Spain. ${ }^{3}$ Department of Environmental Chemistry, IIQAB-CSI, Barcelona, Spain

Received: 30 November 2012 Accepted: 9 May 2013

Published: 31 May 2013

\section{References}

1. Gehring M: Verhalten der endokrin wirksamen Substanz Bisphenol A bei der kommunalen Abwasserentsorgung, Beiträge zu Abfallwirtschaft und Altlasten, Schriftenreihe des Institutes für Abfallwirtschaft und Altlasten der TU Dresden, Bd. 34. Pirna: Forum für Abfallwirtschaft und Altlasten; 2004.

2. Kersten A, Hamm U, Putz H-J, Schnabel S: Wochenblatt für Papierfabrikation 1/2011, Deutscher Fachverlag GmbH, Frankfurt a.M. 14-21.

3. Bilitewski B, Grundmann V, Barcelo D, Ginebreda A, Casal J, Darbra RM, Rydberg T, Benfenati E: Risk-Based Management of Chemicals and Products in a Circular Economy at a Global Scale, Conference proceedings, 8-9 May 2012 Dresden, Germany, Beiträge zu Abfallwirtschaft und Altlasten, Schriftenreihe des Institutes für Abfallwirtschaft und Altlasten der TU Dresden, Bd. 87. Pirna: Forum für Abfallwirtschaft und Altlasten.

4. Bilitewski B, Darbra RM, Barceló D: Global Risk-Based Management of Chemical Additives I (Production, Usage and Environmental Occurrence), The Handbook of Environmental Chemistry, Vol. 18. Heidelberg: Springer Verlag; 2012.

5. Bilitewski B, Darbra RM, Barceló D: Global Risk-Based Management of Chemical Additives II: (Risk-Based Assessment and Management Strategies), The Handbook of Environmental Chemistry, Vol. 23. Heidelberg: Springer Verlag; 2013

\section{doi:10.1186/2190-4715-25-14}

Cite this article as: Grundmann et al:: Risk-based management of chemicals and products in a circular economy at a global scale- Impacts of the FP7 funded project RISKCYCLE. Environmental Sciences Europe 2013 25:14.

\section{Submit your manuscript to a SpringerOpen ${ }^{\odot}$ journal and benefit from:}

- Convenient online submission

- Rigorous peer review

- Immediate publication on acceptance

- Open access: articles freely available online

- High visibility within the field

- Retaining the copyright to your article

Submit your next manuscript at springeropen.com 